\title{
Breast Cancer Surgery and Financial Reimbursement in Germany
}

\author{
Juergen Hoffmann Diethelm Wallwiener \\ University Hospital for Women, University of Tuebingen, Germany
}

\section{Keywords}

German diagnosis-related groups (G-DRG) .

Classification system for oncological, reconstructive and oncoplastic breast surgery - Breast surgery . OPS (operation and treatment procedure classification) 2012 - Reimbursement

\section{Summary}

The reimbursement for breast cancer-specific operative interventions in Germany is regulated by the diagnosisrelated group (DRG) system. The essential elements of the German DRG system, which was developed as a percase lump-sum payment system, are presented, including the participating institutions. The actual treatment situation in breast cancer surgery is now aptly reflected in the introduction of the OPS (operation and treatment procedure classification) 2012. This is oriented on the classification model of Hoffmann and Wallwiener, with its complexity-based differentiation that reflects the basic idea of different resource usage. Despite the actual potential of the appropriately differentiated encryption of surgical procedures, which illustrates their differences in resource costs and consumption, appropriate reimbursement has still not been achieved. Hopefully, in the future the calculation of the DRGs in the field of breast cancer surgery will be based on data feedback from the hospitals and treatment institutions, and will be more suited to the main purpose of the DRG system, i.e. that reimbursement reflects resource expenditure. A necessary basic tool for differentiated, complexity-oriented encryption has been achieved with the OPS 2012, which mirrors our classification model for oncological, oncoplastic and reconstructive breast surgery.

\section{Schlüsselwörter}

G-DRG - Klassifikationssystem der onkologischen, onkoplastischen und rekonstruktiven Brustchirurgie . Brustchirurgie · OPS 2012 - Vergütung

\section{Zusammenfassung}

Die Kostenerstattung für brustkrebsspezifische Eingriffe in Deutschland wird über das Diagnosis-related Groups (DRG)-System geregelt. Die wesentlichen Elemente des G (German)-DRG-Systems als Weiterentwicklung zu einem Fallpauschalensystem werden dargestellt, einschließlich der beteiligten Institutionen. Die der tatsächlichen Behandlungssituation in der Mammakarzinomchirurgie nicht mehr entsprechende Operationenund Prozeduren-Verschlüsselung (OPS) wurde mit der Einführung des OPS 2012, der sich im Bereich der Mammakarzinomchirurgie am Klassifikationsmodell von Hoffmann und Wallwiener mit Komplexitätsdifferierung orientiert, zu einer aktualisierten und dem Grundgedanken des unterschiedlichen Ressourcenverbrauchs verpflichteten Abbildung der therapeutischen Leistungen in diesem Bereich. Trotz der nun möglichen differenzierten Kodierung der operativen Leistungen ist eine entsprechende, dem unterschiedlichen Ressourcenaufwand, bzw. -verbrauch angemessene Vergütung nicht erreicht worden. Es bleibt zu hoffen, dass die Kalkulation der DRG im Bereich der Mammakarzinomchirurgie sich auch auf Basis der Datenrückmeldung der Krankenhäuser und Behandlungsinstitutionen in Zukunft stärker an der eigentlichen Zielsetzung der Vergütung nach dem Ressourcenaufwand orientieren wird. Ein notwendiges Instrument zur differenzierten, komplexitätsorientierten Darstellung der therapeutischen Leistungen ist mit dem OPS 2012 und der Orientierung am «Tübinger Klassifikationsmodell» bereits gegeben.

\section{KARGER \\ Fax +497614520714 \\ Information@Karger.de}

www.karger.com
(C) 2012 S. Karger GmbH, Freiburg

$1661-3791 / 12 / 0075-0384 \$ 38.00 / 0$

Accessible online at:

www.karger.com/brc
Dr. med. Juergen Hoffmann

Brustzentrum der Universitätsfrauenklinik

Klinikum der Eberhard-Karls-Universität Tübingen

CalwerStr. 7, 72076 Tübingen, Germany

J.Hoffmann@med.uni-tuebingen.de 


\section{Introduction: Historical Development and Explanation of the German Diagnosis-Related Group System}

The diagnosis-related group (DRG) system is the term for an economic medical classification system through which the encoded primary and secondary diagnoses, as well as conducted case-related treatment, are identified for each patient in case groups. The corresponding case group classification based on the individual treatment case is forwarded by the service provider (hospital) to the payers (health insurance) for reimbursement. The system was originally developed in 1967 at Yale University in the United States by Fetter and Thompson as a pure classification system for patients and a management tool that allows measurement, evaluation and control of hospital treatment [1]. Its first use as a prospective payment system started in 1983 in the U.S. Medicare program [2].

A further development of the system was implemented in 1992 in Australia for the State of Victoria (Australian refined (AR)-DRG). This version was used as a reference for implementing a similar solution in Germany. In 2000, the administration of the German health care system was requested by the legislature of the Federal Republic of Germany to choose an existing DRG system as a basis for a future German solution. The decision was made in favour of the AR-DRG. Further development of the original medical classification system into a medical reimbursement system was performed by linking the assessment of the severity of a clinical case to the typical corresponding costs for diagnosis and treatment.

The DRG system is an economic medical patient classification system, in which the hospitalized cases are classified into categories after assessing the necessary economic costs for treatment on the basis of their diagnoses and performed treatments. The various DRGs differ due to their clinical contents and resource consumption, and form the basis for financing, budgeting and billing of hospital services. Annual revisions are performed to ensure conformity of the system to the treatment realities in Germany. The institution responsible for annual revision is the Institute for the Hospital Remuneration System in Siegburg (InEK GmbH, Institut für das Entgeltsystem im Krankenhaus) [3].

Prior to the introduction of the DRG-based payment system, inpatient hospital remuneration was based on approximately $80 \%$ of daily care rates and about $20 \%$ of case fees or special charges (mainly in the surgical field). The aim of the DRG system is to represent all somatic inpatient services in a lump-sum payment system that corresponds to the service provided. Since 1 January 2004 it has been obligatory to use the G-DRG system for invoicing in the inpatient health sector. The institutes responsible for the introduction of the lump-sum fee system in accordance with $\S 17$ BKHG (Bundes Krankenhaus Gesetz, Hospital Act) are the German Hospital Federation (Deutsche Krankenhausgesellschaft, DKG), the association of statutory health insurers (Gesetzliche Krankenversicherung, GKV) and the association of private health insurers (Private Krankenversicherung, PKV), who are also shareholders of InEK GmbH.

In the G-DRG system, patients are classified according to medical and patient demographic data (diagnoses, treatment carried out, age, gender, etc.) with the purpose of reckoning the costs into different case groups. The variation of DRGs is due to the determined typical treatment expenses (costs of treatment of an appropriate case). These groups of cases are equipped with an assessment ratio (cost weight, $\mathrm{cw}$ ), which should reflect the different treatment costs of different case groups. The G-DRG catalogue is chaptered into principal diagnosis groups (major diagnostic categories, mdcs), which have an organ-related reference [4]. The mdcs are set up basically related to organs or to aetiology of diseases, generally associated with a particular medical specialty. The relevant mdcs for breast cancer-related surgery are found in the corresponding catalogue under the heading 09: Diseases and disorders of the skin, subcutaneous tissue and breast (G-DRG version 2012, definition manual page 31/32).

The basis for the classification into a relevant mdc are the ICD (International Statistical Classification of Diseases and Related Health Problems) code for the diagnosis (WHO ICD-10 and ICD-10-GM (German version)) [5] and the OPS (Operationen- und Prozedurenschlüssel, the official classification for operation and treatment procedures) code according to the International Classification of the Medical Procedures (ICPM) [6]. A DRG assignment in 1 mdc derives from encryption of IDC and OPS codes using a verified Grouper software for invoicing. This grouper software has to be verified by the InEK.

The DRG code is derived from a 4-digit code. The first digit, a capital letter, indicates the mdc arranged by organs or aetiology of disease. The second and third digits, which are numeric digits, indicate the type of treatment. The last digit, a capital letter, indicates the severity of the DRG (economic) and the cost of treatment, and ranges from A (highest category) to I. The letter $\mathrm{Z}$ indicates that the DRG is not further differentiated.

The billable appropriate lump sum per case, or DRG price, is based on the calculated relative weight or cw multiplied by a so-called base rate, which was initially individually negotiated by the hospital. From 2005 to 2009, a standard for the respective state (national) base rate was developed and aligned. Since 2010 the price for the same treatment is the same in all hospitals within a province, i.e. it does not dependent on the hospital in which the patient was treated. Further adjustments of the uniform state base rates will occur in the next few years with the aim of attaining the same levels nationwide in Germany [7].

An upper and a lower length of stay exist for most DRGs to account for patients who were hospitalized in an appropriate institution for extremely long or particularly short periods. A hospital stay below the lower limit of stay results in a disproportionately high reduction of the lump sum. If the upper 
limit of stay is exceeded, a surcharge on the respective DRG will be reimbursed.

The participating institutions working on the DRG system in Germany are the Federal Ministry of Health (Bundesgesundheitsministerium), DIMDI (German Institute for Medical Documentation and Information), InEK, AWMF (Association of Scientific Medical Societies, an alliance of 163 scientific societies), DKG ( German Hospital Federation), the associations of GKV (statutory health insurances, currently 145 health insurance companies representing about $90 \%$ of the German population) and the associations of private health insurance companies. The last 3 of these institutions are also the shareholders in the InEK GmBH.

The area of responsibility of the DIMDI, based on statutory and related decrees and individual regulations of the Federal Ministry of health, is the publication of official healthrelated classifications for German speaking countries, such as ICD 10 GM (German modification) for diagnosis encryption and OPS for encryption of operations and treatment-related procedures [8].

The ICD is published by the World Health Organization and is used worldwide. The German version is created by the DIMDI, which is also responsible for the OPS for the encryption of all surgical and medical procedures for inpatient care and operative ambulant treatment [9]. This ultimately serves as the basis for the fee system in hospitals and practices in the G-DRG system. The reimbursement of the hospitals according to a clinical case is determined by the product of the $\mathrm{cw}$ and the local base rate.

The DRGs and thus the corresponding amount of reimbursement are calculated annually by the InEK and agreed by its shareholders. The remuneration attached to the DRG is guided by the complexity of the treatment (resource consumption, etc.) [10].

\section{Changes in the Field of Breast Surgery and Breast Cancer Surgery in 2012}

In 2011, the OPS 2012 (valid from 01.01.2012) in the field of surgical intervention to the breast and surgery in the axilla underwent extensive changes. At the institution responsible for OPS, the DIMDI, the classification scheme of breast surgery procedures, according to Hoffmann and Wallwiener, was presented and discussed with representatives of medical associations (German Society for Senology, German Society of Gynaecology and Obstetrics, German Society of Plastic, Reconstructive and Aesthetic Surgery) and representatives of the DIMDI, the InEK, the German Hospital Federation and the MDK (Medzinischer Dienst der Krankenkassen, Medical Service of Health Insurance Companies) [11].

A consensus was reached to use the presented classification model as a basis for further differentiation of the OPS codes in the field of breast surgery. Figure 1 shows the corre-

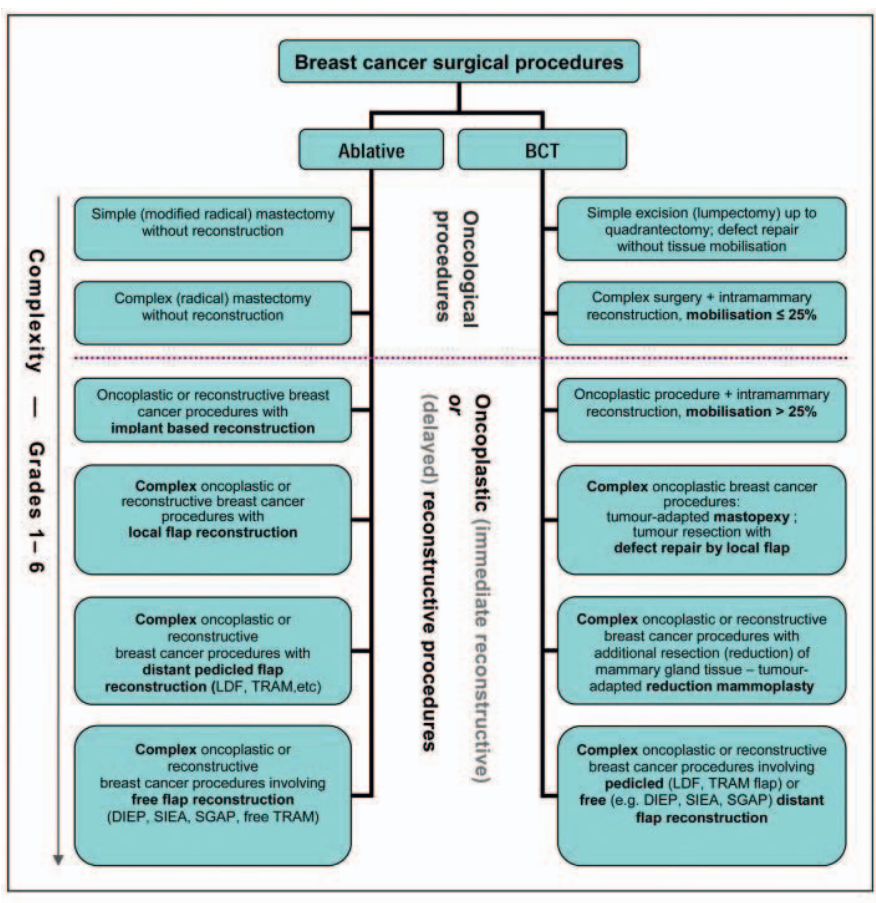

Fig. 1. Complexity-based classification system for oncological, reconstructive and oncoplastic breast surgery for the treatment of breast cancer [11]. BCT = breast conserving treatment.

sponding modified classification system for oncological, oncoplastic and reconstructive procedures relating to breast cancer surgery. An initiative of the German Society of Gynaecology and Obstetrics to encrypt breast cancer surgery-coupled axillary interventions separately from the breast surgical procedure, so that an actual resource consumption-oriented representation of operational performances in breast cancer could be achieved, was also agreed. As a result of the discussions, an official, dedicated proposal for changes to the OPS regarding breast surgery was put forward by Hoffmann and Wallwiener for the German Society for Senology and an official proposal for changes to the OPS regarding a separate coding of axillary surgery was put forward by Schwenzer for the German Society for Gynaecology and Obstetrics. These proposals were then approved, with minor modifications, and introduced in the OPS 2012.

The aim has been to attain an unambiguous assignment of interventions in the breast surgery field, especially in the field of breast-conserving surgery, supplemented by some definitions (tumour-adapted mastopexy, tumour-adapted reduction surgery, etc.) to achieve a clarification of terminology and previously ambiguous codes and to avoid the use of a combination of several codes to describe a defined surgical procedure.

Thus, the classification scheme according to Hoffmann and Wallwiener based on the complexity of ablative surgery and breast-conserving surgery currently represents the basis of the OPS 2012 in the field of breast surgery. In this classification model a distinct differentiation according to the surgical 


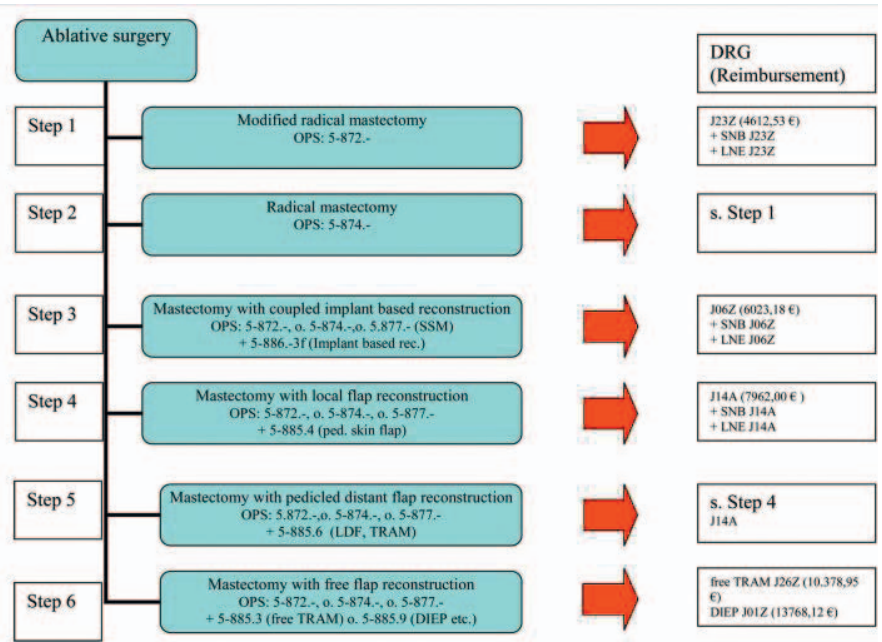

Fig. 2. Ablative breast surgery - translation of the classification system into OPS codes, DRG and reimbursement.

complexity of the procedure is possible and hence the model clearly reflects the consumption of resources. Figure 2 illustrates the concept according to the levels associated with the current OPS procedure code, corresponding to a DRG assignment with the corresponding reimbursement for ablative surgical procedures.

Figure 3 shows similar associations for the breast-conserving surgical therapy area. As it is readily apparent, the complexity of the intervention is reflected inadequately, especially for breast-conserving surgery. Apart from the techniques of volume replacement with defect coverage or compensation through the use of local or distant autologous tissue, all other procedures (volume displacement) lead to the same DRG, regardless of their ascending complexity. The situation regarding the field of ablative breast surgery seems somewhat similar. In this area, interventions of varying complexity are also grouped into the same DRG category, which reflect the consumption of resources inadequately.

For calculation of the tables, the InEK certified Grouper ID Diacos ${ }^{\odot}$ was used with the corresponding assignment to a DRG, and the InEK assigned cw value was multiplied by the respectiveState's base rate (in this case, Baden-Wuerttemberg, currently $€ 3,020.65)$ to calculate the corresponding reimbursement [12].

The classification model for oncological, oncoplastic and reconstructive breast cancer surgical procedures was based on ascending complexity of ablative and breast-conserving procedures in 6 major categories. Other classification criteria for breast surgical interventions, based on the different situations and on the individual factors considered for choosing a treatment method - tumour size, breast size (Size), location (Site), breast shape (Shape) and symmetry issues (Symmetry) - ultimately lead to treatment algorithms that are helpful for the

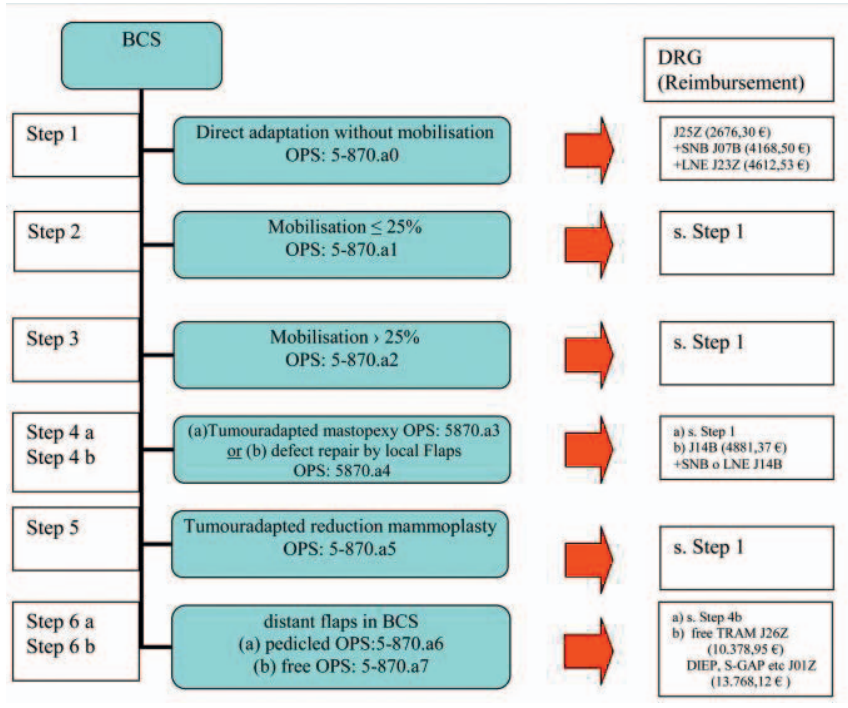

Fig. 3. Breast-conserving surgery - translation of the classification system into OPS codes, DRG and reimbursement. BCT = breast conserving treatment.

selection of individual therapy, but may not clarify scientific issues or may appear unsuitable as a basis for a staged payment [13-15]. Moreover, the term oncoplastic surgery, which is often used differently in national and international literature, was clearly defined in our original publication for a better differentiation of the interventions by levels of complexity: 'the term oncoplastic surgery refers to any surgical procedure in which the primary surgical treatment strategy involves plastic surgical techniques for partial or complete reconstruction of the surgical correction of the breast or for defects to the thoracic wall' [11].

Due to the classification of interventions in increasing order of complexity, the classification model also meets the requirements of the DRG system. It is also possible to use it for medical-economic classification of the treatment, evaluated according to the extent of used resources (economic cost) necessary for treatment (resource consumption).

As shown in the figures, the resource consumption of the institutions according to each category under the current allocation is very inadequate. For example, in ablative surgery, despite the implementation of the classification in the OPS and the very dedicated encoding options, modified radical mastectomy and radical mastectomy lead to the same DRG and the encryption of additional axillary surgery does not lead to a change in reimbursement.

In the field of breast-conserving procedures, all methods of intramammary defect coverage (volume displacement) obtain a higher fee through additive axillary surgery, but ultimately, despite the understandable varying complexity and resource costs, lead to the same DRG for all levels, which in our opinion diametrically contradicts the basic idea of the classification model and the content of a resource-oriented DRG system. 
Only breast-conserving procedures containing a defect coverage by local or distant autologous tissue transfer (volume replacement) reach higher remuneration rates, but these are not increased if additional axillary surgery is required.

\section{Financial Reimbursement of Breast Centres}

The issue of possible under-funding of surgical procedures in the existing G-DRG, particularly in the field of implant-based reconstruction, where the reimbursement by the associated DRG does not enable the institution to cover the costs of the necessary materials (resource consumption), has been pointed out [16]. It is obvious that the corresponding costs have to be subsidized by the departments or hospitals concerned.
The additional costs for establishing and maintaining the structures of certified breast centres in the sense of increasing the quality of care for affected patients also need to be considered [17]. If reimbursement is insufficient, these additional costs must be covered within an institution by cross-subsidization. In this context we hope that the future DRG assessment in breast cancer surgery will align itself more closely to the complexity already achieved in the OPS.

\section{Disclosure Statement}

The authors declare to have no conflicts of interest related to this article.

\section{References}

1 Thompson JD, Fetter RB, Mross CD: Case mix and resource use. Inquiry 1975;12:300-312.

2 Fetter RB: DRGs - Their design and development. Health Administration Press, Ann Arbor, MI, 1991.

3 Institut für Entgelte im Gesundheitswesen (InEK), www.g-drg.de.

4 Fallpauschalen-Katalog 2012, www.g-drg.de/cms/ G-DRG-System_2012/Fallpauschalen-Katalog/ Fallpauschalen-Katalog_2012.

5 ICD-10_GM Version 2012, www.dimdi.de/static/de/ klassi/diagnosen/icd10.

6 OPS Version 2012,www.dimdi.de/static/de/klassi/ prozeduren/ops 301 .

7 Landesbasisfallwerte der Bundesländer (Stand 03.04.2012), www.dkgev.de/media/file/11374. LBFW 20052012 Stand 03042012.pdf.

8 Deutsches Institut für Medizinische Dokumentation und Information (DIMDI), www.dimdi.de

9 G-DRG German Diagnosis Related Groups Version 2012, Definitionshandbuch, Band 3 (DRGs
J01Z-P67D). Institut für das Entgeltsystem im Krankenhaus GmbH (InEK), Siegburg, Germany, 2011.

10 Deutsche Kodierrichtlinien 2012, www.g-drg.de/ cms/G-DRG-System_2012/Kodierrichtlinien/ Deutsche_Kodierrichtlinien_2012.

11 Hoffmann J, Wallwiener D: Classifying breast cancer surgery: A novel, complexity-based system for oncological, oncoplastic and reconstructive procedures, and proof of principle by anlysis of 1225 operations in 1166 patients. BMC Cancer 2009;9:108-116.

12 Grouper/Zertifizierung 2012, Zertifizierte Grouper G-DRG Version 2012, www.g-drg.de/cms/G-DRGSystem_2012/Grouper_Zertifizierung/Grouper Zertifizierung_2012.

13 Clough KB, Cuminet J, Fitoussi A, et al.: Cosmetic sequelae after conservative treatment for breast cancer: classification and results of surgical correction. Ann Plast Surg 1998;41:471-481.
14 Clough KB, Thomas SS, Fitoussi AD, et al.: Reconstruction after conservative treatment for breast cancer: Cosmetic sequelae classification revisited. Plast Reconstr Surg 2004;114:1743-1753.

15 Munhoz AM, Montag E, Arruda E, et al.: Assessment of immediate breast surgery reconstruction: A classification system of defects revisited and an algorithm for selecting the appropriate technique. Plast Reconstr Surg 2008;121:716-727.

16 Jacobs VR, Rasche L, Harbeck N, et al.: Underfinancing of $90.3 \%$ for implant costs of prostheses and expanders in DRG revenues for uni- and bilateral mastectomy with immediate breast reconstruction. Onkologie 2010;33:584-588.

17 Beckmann MW, Bani MR, Loehberg CR, et al.: Are certified breast centres cost-effective? Breast Care 2009;4:245-250. 